\title{
Inhalt des sechs und zwanzigsten Bandes.
}

\author{
E r s t e s H e f t.
}

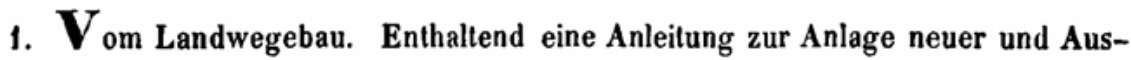
besserung vorhandener Landwege, in den gewöhnlichsten Fällen. Von Herrn Landgüter-Verwalter J. H. Schmidt, jetzt in Pommern. . . . . Seite 1

2. Übersicht der Geschichte der Baukunst, mit Rücksicht auf die allgemeine Culturgeschichte. Von Herrn Regierungs- und Baurath C. A. Rosenthal zu Magdeburg. (Fortsetzung der Abhandlung No. 2., 6. und 8. im 13ten, No. 1., 7., 8. und 12. im 14ten, No. 1., 9., 11. und 15. im 15ten, No. 10. im 16ten, No. 3., 5. und 10. im 17ten, No. 4. im 18ten, No. 2. im 20ten, No. 9. im 22ten, No. 1., 9. und 13. im 25ten Bande.) . . . . . . . -48

\section{Z w e i tes H e f $t$.}

3. Des Grafen v. Pambour ,'Theorie der Dampfmaschinen." Nach der zweiten Auflage dieses Werkes von 1844; möglichst kurz; und mit einigen Anmerkungen des Herausgebers dieses Journals. (Fortsetzung der Abhandlung No. 8. und 12. im 23ten, No. 3., 5. und 9. im 24ten, No. 5. und 11.

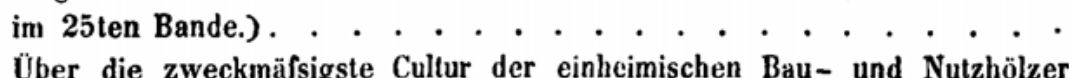

4. Über die zweckmäfsigste Cultur der einheimischen Bau- und Nutzhölzer.
Von J. H. Schmidt, Landgüter-Verwalter, jetzt in Pommern. . . . .

5. Auswahl von Abhandlungen berühmter niederländischer Wasserbaukundiger über die Wasserbaue, welche in Holland an den Hauptströmen zum Schutze gegen Verwüstung nöthig sein werden. Aus dem Holländischen übersetzt und mit einer Einleitung und Anmerkungen begleitet von Herrn Dr. Rcinhold, Königl. Hannöverschem Wasserbau-Inspector; so wie mit einigen Anmerkungen des Herausgebers dieses Journals. (Fortsetzung der Abhandlung No. 4. und 11. im 24ten und No.3., 7. und 10. im 25ten Bande.) . .

\section{D r it t e s $H$ e f t.}

b. Einige technische Notizen. Yon Herrn $\boldsymbol{W}$. Emmich, Königlichem BauInspector und Ingenieur-Premier-Lieutenant a. D.

I. Über die Entstehung, Verhülung und Vertreibung des sogenannten

Hausschwammes. . . . . . . . . . . . . . . . . . . -193

II. Eine Verbesserung der Pisémauern. . . . . . . . . . . . -198

III. Über die Sicherung des Rohrs gegen die Einwirkung des Feuers. . $\quad 199$

IV. Bemerkungen über die Mittel zur Verlängerung der Dauer des Holzes. -200

V. Bemerkungen über die Bauart mit Kalksandmasse. . . . . . . -201 
7. Vom Landwegebau. Enthaltend eine Anleitung zur Anlage neuer und Ausbesserung vorhandener Landwege, in den gewöhnlichsten Fällen. Von Herrn Landgüter-Verwalter J. H. Schmidt, jetzt in Pommern. (Schlufs der Abhandlung No. 1. in diesem Bande.) . . . . . . . . . . . Seile 204

๖. Auswahl von Abhandlungen berühmter nicderländischer Wasserbaukundiger über die Wasserbaue, welche in Holland an den Hauptströmen zum Schutze gegen Verwüstung nöthig sein werden. Aus dem Holländischen übersetzt und mit einer Einleitung und Anmerkungen begleitet von Herrn Dr. Reinhold, Königl. Hannöverschem Wasserbau-Inspector; so wie mit einigen Anmerkungen des Herausgébers dieses Journals. (Fortsetzung der Abhandlungen No.4. und 11. im 24ten, No.3., 7. und 10. im 25ten und No.5. in diesem Bande.) - 25s

$$
\text { V i e r t e s } H \text { e } f t \text {. }
$$

9. Hohle eiserne Pfähle durch die Spannkraft der Luft in den Boden zu treiben. $-285$

10. Auswahl von Abhandlungen berühmter niederländischer Wasserbaukundiger über die Wasserbaue, welche in Holland an den Hauptströmen zum Schutze gegen Verwüstung nöthig sein werden. Aus dem Holländischen übersetzt und mit einer Einleitung und Anmerkungen begleitet von Herrn Dr. Reinhold, Königl. Hannōverschem Wasserbau-Inspector; so wie mit einigen Anmerkungen des Herausgebers dieses Journals. (Schlufs der Abhandlung No. 4. und 11. im 24ten, No. 3., 7. und 10. im 25ten, No. 5. und 8. in diesem Bande.)

11. Uber die zweckmäfsigste Cultur der einheimischen Bau- und Nutzhölzer. Von J. H. Schmidt, Landgüter-Verwalter, jetzt in Pommern. (Fortsetzung

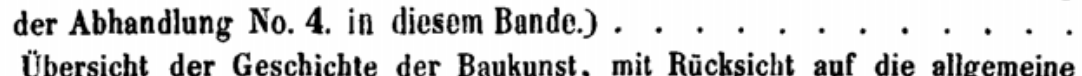

12. Übersicht der Geschichte der Baukunst, mit Rücksicht auf die allgemeine Culturgeschichte. Von Herrn Regierungs- und Baurath C. A. Rosenthal zu Magdeburg. (Fortsetzung der Ablsandlung No. 2., 6. und 8. im 13ten, No. 1., 7., 8. und 12. im 14ten, No. 1., 9., 11. und 15. im 15ten, No. 10. im 16ten, No.3., 5. und 10. im 17ten, No. 4. im 18ten, No. 2. im 20ten, No. 9. im 22ten, No. 1., 9. und 13. im 25ten und No. 2. in diesem Bande.) . . - 351 


\section{J o u r n a l}

f ü r

\section{d i e Ba uk u n s t. \\ I n z w a n g l o s e n H e f t e n.}

Herausgegeben

vo n

\section{Dr. A. L. Crelle,}

Kininglich-Pretifsischem Geheimen-Ober-Baurathe, Mitgliede der Küniglichen thademie der Wissenschaften zu Berlın, Correspondenten der Kaiserlichen Akademie der Wissenschaften zu St. Petersburg und der Küniglichen Aikademieen der Wissenschaften zu Neapel und Brüssel, auswärligem Mitgliede der Königlichen Akademie der Wissenschaften zu Stockholm, Ehrenmitgliede der Hamburger Gesellschaft zur Verbreitung der mathematischen Wissenschaften.

\section{Sechs und zwanzigster Band.}

Erstes Heft.

Mitzwei Figurentafeln.

$$
\text { B e r } 1 \text { i n. }
$$

B e i G. R e $i$ in e $r$.

1847. 
